\title{
Challenges with Coordination of Technology Development and Transfer of Industry 4.0 Technologies in IMNs
}

\author{
Viktorija BADASJANE $^{\mathrm{a}, 1}$, Mats ALHSKOG ${ }^{\mathrm{a}}$, Anna GRANLUND ${ }^{\mathrm{a}}$ \\ and Jessica BRUCH ${ }^{\mathrm{a}}$ \\ ${ }^{a}$ Department of Innovation and Product Realization, Mälardalen University, Sweden
}

\begin{abstract}
Within an international manufacturing network (IMN), one particular factory, called the lead factory is responsible for development of new products, processes and technologies as well as transferring these to the subsidiaries within the IMN. These responsibilities require coordination, which is found difficult even in the best-performing companies due to its complexity. When the responsibility for development of Industry 4.0 technologies are included such as cyber-physical systems and Internet of Things the complexity increases further. Therefore, the aim of this paper is to identify what are the challenges with coordination of technology development and transfer of Industry 4.0 technologies in IMNs. Accordingly, a realtime embedded case study was carried out with six manufacturing companies. One major finding is that development of Industry 4.0 technologies does not fit the current way of organizing technology development at lead factories. Another finding is that several of the identified challenges connected to technology development can be derived from a lack of a long-term strategy ensuring competence for future needs.
\end{abstract}

Keywords. Production, Lead factory, International manufacturing networks

\section{Introduction}

Competitive advantage can be gained in global manufacturing companies by aggregating factories that are located in different parts of the globe into international manufacturing networks (IMNs) [1]. The benefits of IMNs are an enhanced possibility of achieving higher production flexibility as well as have better preconditions of responding to emerging business challenges [2]. However, a prerequisite for harnessing the advantages of globalization, is that the factories must be considered as a part of an integrated global network [3] which requires a network focus rather than a factory focus [4-6].

The factories in an IMN can take on different strategic roles [6-8]. One particular factory, called the lead factory, is responsible for creating new processes, products and technologies, and is therefore a global hub for product or process knowledge that can create value for the entire network when transferred within the IMN [3]. Additionally, synergy as well as performance consistency can be achieved when manufacturing processes are transferred to the subsidiaries in the IMN [9] which entails continues

\footnotetext{
${ }^{1}$ Viktorija.badasjane@mdh.se
} 
transfer of knowledge and information about modification of products and changes of the manufacturing system [8].

These lead factory responsibilities require coordination of the IMN - here addressing the infrastructural links between factories [10]. Coordination is of equal importance as the strategic location of the factories within an IMN [11]; it includes decisions made regarding the interactions of factories in the IMN [12], and serves the purpose of achieving an efficient and effective plan for the exchange of knowledge and resources [2,13]. Yet, even the best-performing companies find coordination to be particularly challenging due to the complexity of the task [10] because this includes a constant development and assessment of interdependencies between the factories $[4,10$, 14] as well as increase of complexity when the number of factories and organizations is large [4]. Adding on the development of novel Industry 4.0 technologies the complexity of coordinating the IMN increases further [15]. Lead factories need to deal with rapid technology changes derived from Industry 4.0, including state-of-the-art technologies such as cyber-physical systems and Internet of Things (IoT) [16], this puts pressure on IMNs [17]. For instance, increase of digital connectivity, human-machine collaboration, and visualization via digital aid is identified as disruptive attributes of Industry 4.0 [18]. Yet the methods, principles, and technologies within Industry 4.0 has the potential to make the production systems more autonomous, dynamic [19] as well as provide flexibility and accuracy [20]; but this requires new competences [20-22]. Understanding of the term Industry 4.0 is perceived as a difficulty in manufacturing companies [23]. Here, the Industry 4.0 technologies refer to advanced digital technological innovations, which when combined can enable novel digital industrial technology [24].

The manner in which development of Industry 4.0 technologies can be coordinated in IMNs has gained limited research attention [15], especially important is the technology development and transfer which is performed by the lead factory and is a resource extensive task [25]. The enabling Industry 4.0 design principles (e.g. Manufacturing as a Service) and technologies (e.g. IoT) have been used in industry as well as been researched for almost a decade [23]. However, to stay competitive, a strategic roadmap visualizing each step toward Industry 4.0 maturity within a company is required from a strategic and technology perspectives [26]. Nevertheless, the development and transfer of Industry 4.0 technologies have not been connected to the IMN perspective in previous research, which leaves a gap affecting also the coordination of IMNs. Therefore, the aim of this paper is to identify what are the challenges with coordination of technology development and transfer of Industry 4.0 technologies in IMNs.

\section{Theoretical background}

The factories within an IMN have different roles to play and must develop capabilities that corresponds to their particular role in the network. By developing the capabilities, the factories can achieve a higher role within the IMN [27]. Moreover, factory-specific capabilities can be used for classifying the factories [2, 27], where the most recognized framework is presented by Ferdows [3,6] who classify six generic roles for factories based on both capabilities and the strategic reason of the site, the highest one being the lead factory. The roles of the factories in an IMN is however not static [28] because changes in one factory can result in redistribution of responsibilities as well as affecting the structure of the network [11]. 
The lead factory responsibility includes production development and ensuring that the developed knowledge is disseminated into the IMN [29]. The knowledge can be associated with both production, Industry 4.0 technologies as well as best practice. Yet, development of technology requires extensive process innovation capabilities, and capacity to integrate new technologies and procedures into production [30]. As the lead factory is the knowledge creator that provides the IMN with solutions, the development activities requires collaboration between for instance the lead factory and R\&D for product development [31].

Technology transfer is here defined as the process of dissemination and retention of technologies which can be intangible (e.g. knowledge, experience), and/or tangible (e.g. product, prototype) [32]. Whether the knowledge generated connected to processes or technology is eligible for transfer is depended upon the complexity of the production processes and the heterogeneity of the factories in the IMN [33]. Thus, technology transfer is generally considered to be an extremely complex process [34].

\subsection{Coordination of the IMN}

A major incentive for companies to aggregate their factories into IMNs is the gained access to technological resources and knowledge across factories [7]. As such, the manner in which knowledge and technology is shared is especially important in order to coordinate [12]; which can in turn strengthen the competences across the IMN [35], affect the overall performance of the network [2,36], and improve process and product design by sharing knowledge, resources, and capabilities instead of conducting separate development at individual factories [14]. Hence, coordination is a prerequisite for integration of; material flows, management skills, product or process development, and knowledge [14, 37].

Coordination of an IMN can be divided into two categories; governance, meaning the structures that direct and control the IMN (e.g. leadership structures, performance measurement, decision-making) and operations processes (e.g. management of materials, information and knowledge flows across factories) [38]. However, there is also a need to establish global operational plans [39] and strategies [8] in order to coordinate decisions and activities [39]. Furthermore, coordination entails that the lead factory provides support for the subsidiaries. Yet the manner of support it provides for the subsidiaries must be adjusted according to the difference within the subsidiaries experience, competence, resources and technology maturity. All of which affects the extent and degree of needed support from the lead factory, and requires that the lead factory achieve an understanding of the subsidiaries needs and competences [25].

\subsection{Industry 4.0 technologies}

Application of cyber physical systems within industrial production systems is a common way of viewing Industry 4.0 [40]. Transition toward Industry 4.0 poses multiple challenges for companies, e.g. capacity to innovate, new strategies and organizational models etc. [24]. Therefore, companies that strive to transition toward a smart factory need a formation of a roadmap which is based on the company's core competencies, motivations, capabilities, intent, goals and priorities [23]. Furthermore, the design principles of Industry 4.0 can guide manufacturers in their efforts by addressing the necessary knowledge required for developing procedures and solutions [24]. 
Industry 4.0 technologies can provide competitive advantages of cost and time efficiency [41] but firstly it requires an effective integrations between personnel, processes, equipment, and products [42]. Additional requirements are of; removal of functional silos, openness to change, supportive culture, and data transparency across the value chain. However, for IMNs this transition demands a period of time and cannot be achieved in the short run [23]. Another important aspect is identifying the needed competence for Industry 4.0 technologies as well as competence gaps; this can performed by an assessment tool which weighs the specific company needs to the needed abilities [20].

\section{Research design}

Since the purpose of this paper was to identify what are the challenges with coordination of technology development and transfer of Industry 4.0 technologies in IMNs, a realtime embedded case study was carried out. A case study method was chosen because it can provide a detailed understanding of the phenomenon studied [43-45] and it provides the opportunity to use different techniques for data collection and sourcing of data supporting the ability to gather a rich set of data [46].

Six different companies from the manufacturing industry was selected for this study. The participants in this study worked at eight lead factories with technology development and transfer of Industry 4.0 technologies in IMNs. Generally, the participants had a global position at their respective company and each company was represented by one or two participants. The companies belonged to the following industries; pharmaceutical, rail, automotive, heavy vehicle, aerospace and precision steel.

\subsection{Data collection}

Data have been collected through focus group interviews. The focus group approach can provide observations of interactions between individuals [45] and this approach was selected since it facilitated exchange of experience and knowledge between foremost the participants and provided a rich amount of data. Moreover, the participants could reflect about the overall theme of the interviews; operating as a lead factory. Although multiple focus group interviews were held, only four interviews were included in this study because the content corresponded to the aim of this study. The focus groups were held during 2018-2019.

Table 1. Description of the focus groups

\begin{tabular}{llll}
\hline $\begin{array}{l}\text { Focus } \\
\text { group }\end{array}$ & $\begin{array}{l}\text { Interview } \\
\text { approach }\end{array}$ & Preparation of questions & Topics of discussion \\
\hline 1 & Open-ended & All companies, selected by researchers & $\begin{array}{l}\text { Competence for Industry } 4.0 \\
\text { technologies }\end{array}$ \\
\hline 2 & Open-ended & Hosting company, supported by researchers & Lead factory responsibilities \\
\hline 3 & Unstructured & None & Open discussion \\
\hline 4 & Open-ended & Hosting company, supported by researchers & Industry 4.0 technologies \\
\hline
\end{tabular}

The focus group interviews were held at the participating companies' lead factories in Sweden and the total duration of the sessions were approximately eight hours each. 
The topics of discussions were decided in multiple ways. At the first focus group interview, all companies could send in discussion questions beforehand which were connected to the challenges they experienced related to their lead factory role. The researchers conducting this study selected the submitted discussion questions according to the majority rule. The topic of discussion at this session was thereby competence for Industry 4.0 technologies. The researchers firstly provided the participants a theoretical background connected to competence, introduced the questions for discussion connected to this topic, and acted as a moderator during the discussions.

At both the second and fourth focus group interview, the hosting company prepared discussion questions beforehand. The researchers' role was to support the companies to develop the discussion questions, however, the companies were allowed space to select the topics related to their specific challenges. This approach was chosen as the potential benefits could be that the participants could receive novel perspectives to their specific challenges in the interaction in the focus group. The topics for discussion was the responsibilities accredited to the lead factory connected to technology development and transfer, and Industry 4.0 technologies respectively.

Furthermore, during the second and third focus group interview, the discussions were performed firstly in diverse smaller groups, secondly the researchers presented a summarization of the discussions, and thirdly a discussion by all company participants was held. Number of smaller groups were equivalent to number of participating researchers. This approach was chosen to facilitate deeper discussions among the participating company representatives, as well as to allow more room for participation for each individual. The researchers' role was predetermined to observing and notetaking, and participating in the discussions to a limited degree, only to intervene when the discussions impasses. The same approach was applied during the fourth focus group. Lastly, at the third focus group, the discussion was not predetermined, that is, the participating companies could raise their own topics during the focus group. The developed open-ended questions in three of the focus groups acted more as a guidance than a traditional interview. All focus group interviews were informal and allowed for spontaneous responses from the participants. This approach, according to Wertz et al. [45] and Williamson [47] allows for a spontaneous exploration of the research topic.

\subsection{Data analysis}

Data analysis was performed in several steps. First, notes from each focus group interview were read through to receive an overview of the content. Second, data was sorted and arranged in themes correlating to either challenges with technology development or transfer in general and within the context of Industry 4.0 specifically. This allowed for an arrangement of data into categories [45]. Furthermore, the data analyses could provide a comparison between the participating companies. A cross-case analysis was therefore performed to enable generalization of the findings [48]. Finally, the empirical findings were compared with the key findings from the literature review [49]. 


\section{Results}

The findings of this paper are categorized into; challenges with Industry 4.0 technology development, and challenges with transfer of Industry 4.0 technologies. Table 2 provides a summarization of the challenges presented in heading 3.1 and 3.2.

Table 2. Challenges with coordination of development and transfer of Industry 4.0 technologies

\begin{tabular}{ll}
\multicolumn{1}{c}{ CHALLENGES } \\
\hline \multicolumn{1}{c}{ Technology development } & \multicolumn{1}{c}{ Technology transfer } \\
\hline $\begin{array}{l}\text { Lack of overview over technology development in } \\
\text { the IMN }\end{array}$ & $\begin{array}{l}\text { Lack of competence regarding transfer of Industry } \\
4.0 \text { technologies }\end{array}$ \\
\hline $\begin{array}{l}\text { Balancing development for local factory need } \\
\text { contra global IMN need }\end{array}$ & $\begin{array}{l}\text { Lack of resources regarding transfer of Industry 4.0 } \\
\text { technologies }\end{array}$ \\
\hline $\begin{array}{l}\text { Uneven technology development progress in the } \\
\text { IMN }\end{array}$ & $\begin{array}{l}\text { Dependence on network managers for transfer of } \\
\text { knowledge from the subsidiaries }\end{array}$ \\
\hline $\begin{array}{l}\text { Existing way of working with technology } \\
\text { development does not fit in the Industry 4.0 } \\
\text { context }\end{array}$ & $\begin{array}{l}\text { Heterogeneity of processes between the lead factory } \\
\text { and subsidiaries }\end{array}$ \\
\hline $\begin{array}{l}\text { Lack of interrelation between production and } \\
\text { product strategy }\end{array}$ & $\begin{array}{l}\text { Different levels of automation within the IMN } \\
\text { requires a broad level of competence at the lead } \\
\text { factory to provide support }\end{array}$ \\
\hline $\begin{array}{l}\text { Lack of long-term strategy for ensuring } \\
\text { competence for future need }\end{array}$ & $\begin{array}{l}\text { Incompatible systems and different ways of } \\
\text { working }\end{array}$ \\
\hline $\begin{array}{l}\text { Difficulty to gain a horizontal overview regarding } \\
\text { knowledge and competence }\end{array}$ & $\begin{array}{l}\text { Resistance among the operators to apply Industry } \\
\text { 4.0 technology }\end{array}$ \\
\hline
\end{tabular}

\subsection{Challenges with Industry 4.0 technology development}

The lead factory role is dynamic and new responsibilities can be assigned as shown in one participating company that has received the responsibility over development of Industry 4.0 technologies within its IMN. However, this attributed responsibility is foremost applied to create production solutions that fits this particular lead factory and its product segment. Deciding when to develop for the local need contra when to develop for the global dissemination into the IMN is commonly viewed as a difficulty among the participating companies. As the participating companies have a lead factory role, support subsidiaries that are interested in applying the novel Industry 4.0 technologies is one of the tasks associated with this role. However, as the lead factory is further ahead regarding technology development compared to the subsidiaries, new projects are not necessary prioritized as top management can prioritize that subsidiaries firstly catch up. Specifically, coordination and having an overview over all technical development within the IMN is related to difficulties. The network configuration where several lead factories exist in an IMN and possesses responsibility over a product segment, can result in conflict of focus or misalignment. Hence, coordination between the lead factories in an IMN can be lacking regarding development of technology. However, as the development of technology is occurring more rapidly, coordination of the IMN becomes increasingly important and is viewed as an ever more important topic among the participating companies. 
In one of the participating companies it was realized in 2007 that the way of working with production technology development does not support how the company handles the emergence of Industry 4.0 technologies. It was recognized that production needs to be involved early in product development and establish a long-term plan which duration is between 2-10 years. In order for production to be prepared for the next generations of products, the connection between production and product strategies is deemed to be necessary.

Commonly, among the participating companies, a long-term strategy for ensuring competence for future need is lacking. This can be a consequence of the lack of interrelation between production and product strategy. A challenge for the participating companies is thus to evaluate the current needed competence level as well as what competences will be needed in a future setting. A common solution for this is to map out the current competences needed for blue-collar workers. However, this solution does not provide a holistic overview nor what competences are needed in all positions. A means to face this issues in one participating company is to establish an internal platform which allows evaluation on individual level, defines what competences will be needed and produces learning material that can be used by workers. Gaps has thus been identified between current and future competence on some levels of the lead factory, yet a structure for how to proceed is lacking. Also, there is no demand from top management that a structure should be in place, rather, this issue is driven from an internal need at this lead factory.

One major risks is to develop knowledge but lack a structure to maintain it in employees on all levels. A common challenge is to attribute responsibility beyond managers over critical competence areas as these positions can have difficulties to attain and manage the knowledge. A general challenge for the participating companies is to gain an overlook horizontally in a factory's functions regarding existing knowledge and competence. The horizontal overview is however, viewed as important due to the need for cross-functional competence and total assessment of it in all functions. From a production viewpoint, each function should have understanding and insight into production. The risks of the lack of a holistic competence overview is that an operator can have greater competence than a white collar worker, however this is not portrayed and the available resources are not used in the most efficient way.

\subsection{Challenges with transfer of Industry 4.0 technologies}

Transfer of technology or production related to Industry 4.0 is in one participating company associated with lack of competence and resources. Specifically, it is viewed as difficult to coordinate how the exchange of knowledge and dissemination of the developed technology is performed. Similarly, information from improvement projects performed at the subsidiaries is dependent on capable network managers that can combine the information and spread it within the IMN to facilitate development of global standards. However, multiple challenges for transferring technology development from the lead factory to the subsidiaries are identified within the participating companies. The challenges can be heterogeneity of processes, different levels of automations between sites, incompatible systems, or different ways of working. These aspects are viewed as obstacles that prevent technology transfer directly between sites. As the lead factory role incorporate providing support for the subsidiaries, it is deemed to be valuable that the lead factory can possess the right competence that is adjusted for the need of the network. Even though the factory itself can have mostly manual assembly of highly customized 
products, there is a need to possess competence regarding both manual and automated processes in order to provide support to subsidiaries. Also, sharing the development should according to one participating company be centrally financed to provide an incentive to perform the technology transfer task. Furthermore, resistance is observed in the operators regarding applying novel Industry 4.0 technology.

From a lead factory perspective, it is viewed that the ability to manage a high level of collaboration with subsidiaries and other units, which also involves bridging hierarchical boundaries as well as solving complex problem in a cross-functional manner is increasingly important. This lead factory competence is viewed by one participating company as at least as important as the technical development and can be facilitated by sharing information when it is needed and thereby minimize the lead time for problem solving. In project management that extends to and involves multiple factories, it is essential that new information and plans becomes available for all involved employees.

\section{Discussion and implications}

In an IMN, the development and transfer of technology is generally performed at the lead factory, a fact present in both previous research [29-31] as well as in findings in this paper. Global companies are forced to adapt in order to keep up with the trends associated with Industry 4.0 and this is connected to a number of challenges and prerequisites [26]. This paper identifies the challenges with coordination of technology development and transfer of Industry 4.0 technologies in IMNs.

\subsection{Theoretical implications}

One major finding is that development of Industry 4.0 technologies does not fit the current way of organizing technology development at lead factories. Two approaches emerged from the participating companies for tackling technology development in this context. One participating company recognized early that the manner in which technology development is performed needs to be adapted in relation to emergence of Industry 4.0. Here, a long-term strategy for technology development was established. However, the change included also an early involvement of production in product development as a prerequisite for establishing the long-term strategy. This is in line with Ghobakhloo [23] who point out that the transition toward Industry 4.0 should be managed by establishment of a roadmap that takes into consideration the companyspecific attributes. As well as Gilchrist [24] who highlights the need of new strategies and organizational models.

Another participating company was assigned Industry 4.0 responsibility in its IMN, but this alone did not ensure that the technology development was performed with the need of the IMN in mind. This contradicts previous research accrediting the lead factory with development intended for dissemination within the IMN [29]. Rather, as the technology development is unbalanced in the IMN of this participating company, where the lead factories are further ahead possibly due to their role. A consequence for one participating company is that new technology development projects is not prioritized in order to leave room for the subsidiaries to catch up. Because the lead factory has the responsibility to integrate new technology into operations [30] and provide the IMN with technological resources and knowledge [7], it can be argued that the unbalanced technology development is a challenge that needs to be overcome in order to strengthen 
the potential effects gained by coordinating technology development in the IMN $[2,14$, $35,36]$. Moreover, an important challenge for several participating companies is the lack of overview over the technology development performed in the IMN. However, it is realized that coordination of technology development is increasingly important, especially to avoid conflict of focus or misalignment between the lead factories in an IMN.

Several of the identified challenges connected to technology development can be derived from a lack of a long-term strategy for ensuring competence for future needs. One participating company has established an evaluation tool between current competence and needed competence in the future, yet lacks demand from top management to broaden this structure to all employees. Generally, a horizontal overview over knowledge and competence in all factory's functions is lacking in all participating companies. Two of the participating companies have established structures for competence evaluation, yet it is confined to blue-collar workers. However, previous research pinpoints that Industry 4.0 can be disruptive [18] and requires new competences [20-22] and competence gaps should be identified according to the specific company needs [20]. It can therefore be argued that although the participating companies realize on management level the need for a structured overview of the required future competences, this need is not yet conveyed to the top management.

The technology transfer is connected by the sort of development that was performed in the first place, whether the development was performed solely for local fit or also intended for global transfer in the IMN. This can be traced back to the lack of organizing prior to technology development which in the later stages affects the manner in which technology transfer is performed or if the transfer is possible in the first place.

Because technology development is not necessary balanced between the local lead factory need and the global IMN need, the development can be performed solely with the lead factory need in mind. Therefore, transfer can be connected with several challenges which are summarized in table 2, such as heterogeneity of processes between the factories, incompatible systems, different ways of working, possessing the right competence to provide the right support etc. Thus, previous research consider technology transfer to be an extremely complex process [34] which is dependent on the heterogeneity of the factories in the IMN [33]. The findings of this paper connected to Industry 4.0 technology transfer are therefore not strictly related to these technologies per se. Rather, the transfer activity in general in the examined lead factories is connected to difficulties and also here Industry 4.0 adds complexity. Therefore, it can be argued that the identified challenges for transfer of Industry 4.0 technologies in the IMN, are not limited solely to Industry 4.0 technologies within the participating companies. Rather, if basic structures for technology transfer are not developed prior to adding the complexity of Industry 4.0, the total complexity of the transfer task increases. Especially as identified in one participating company, competence and resources for transfer of Industry 4.0 technologies is lacking.

\subsection{Managerial implications}

Besides from identification of the challenges with coordination of technology development and transfer of Industry 4.0 technologies in IMNs, this study identifies a possible root cause behind the challenges, that is; development of Industry 4.0 technologies does not fit the current way of organizing technology development at lead factories. A possible consequence is that technology development at lead factories is 
performed solely for the local need, which potentially can be avoided by firstly establishing a technology roadmap such as presented by Ghobakhloo [23]. Hence possibly avoiding the identified challenges connected to technology development in this study, as well as the effects they can have on the transfer of Industry 4.0 technologies that follows. Adapting the technology development for Industry 4.0 can furthermore provide an overview over all development projects conducted in the IMN, thus increase the coordination of activities, resources and efforts.

\subsection{Limitations and further research}

The findings in this study are based on data collected in four focus group interviews with managerial representatives from eight lead factories in Sweden. This method provides a broad amount of challenges from the perspective of different companies in order to fulfil the aim of this study. However, the challenges are described to a limited degree. To gain a comprehensive understanding about what challenges exist but also how global companies have approached them and what solutions have been developed, more research is needed and would require in-depth studies. Also, different Industry 4.0 technologies are arguably connected to specific challenges which was not investigated in this study. Furthermore, the lead factories examined in this study have different contexts and the Industry 4.0 efforts vary, that is, a minority of the lead factories have come further along in their Industry 4.0 efforts compared with other examined lead factories that are in the brink of their efforts.

The need for performing technology development in an intentional and organized manner is here identified as the major challenge that has ripple effects also for transfer of Industry 4.0 technologies in the IMN. However, there is a gap in previous research that investigates how the technology development in IMN can be organized, thus finding support for how to strategically perform this task is difficult both from managerial and academic points of view.

\section{References}

[1] K. Ferdows, Made in the world: the global spread of production, Production and Operations Management, vol. 6, no. 2, pp. 102-109, 1997.

[2] Y. Cheng, S. Farooq, and J. Johansen, Manufacturing network evolution: a manufacturing plant perspective, International Journal of Operations \& Production Management, vol. 31, no. 12, pp. 1311-1331, 2011.

[3] K. Ferdows, Making the most of foreign factories, Harvard Business Rewiew, vol. 75, no. 2, pp. 7388, 1997.

[4] M. Rudberg and J. Olhager, Manufacturing networks and supply chains: An operations strategy perspective, Omega, vol. 31, no. 1, pp. 29-39, 2003.

[5] Y. Shi, Internationalisation and evolution of manufacturing systems: classic process models, new industrial issues, and academic challenges, Integrated Manufacturing Systems, vol. 14, no. 4, pp. 357-368, 2003.

[6] K. Ferdows, Mapping international factory networks, in Managing International Manufacturing, K. Ferdows, Ed. Amsterdam: Elsevier Science Publishers, 1989, pp. 3-21.

[7] A. Vereecke, R. Van Dierdonck, and A. De Meyer, A typology of plants in global manufacturing networks, Management Science, vol. 52, no. 11, pp. 1737-1750, 2006.

[8] M. Rudberg and M. B. West, Global operations strategy: coordinating manufacturing networks, The International Journal of Management Science, vol. 36, no. 2008, pp. 91-106, 2008.

[9] I. Y. Lu, C. J. Mao, and C. H. Wang, Intrafirm technology and knowledge transfer: a best practice perspective, International Journal of Technology Management, vol. 49, no. 4, pp. 338-345, 2010.

[10] Y. Shi and M. Gregory, International manufacturing networks - to develop global competitive 
capabilities, Journal of Operations Management, vol. 16, no. 2/3, pp. 195-214, 1998.

[11] A. Feldmann, J. Olhager, D. Fleet, and Y. Shi, Linking networks and plant roles: the impact of changing a plant role, Journal of Production Research, vol. 51, no. 19, pp. 5696-5710, 2013.

[12] T. Friedli, A. Mundt, and S. Thomas, Strategic management of global manufacturing networks: aligning strategy, configuration, and coordination. Berlin, Heidelberg: Springer-Verlag Berlin Heidelberg, 2014.

[13] T. H. Netland and A. Aspelund, Multi-plant improvement programmes: a literature review and research agenda, International Jornal of Operations \& Production Management, vol. 34, no. 3, pp. 390-418, 2014.

[14] Y. Cheng, A. Chaudhuri, and S. Farooq, Interplant coordination, supply chain integration, and operational performance of a plant in a manufacturing network: a mediation analysis, Supply Chain Management: An International Journal, vol. 21, no. 5, pp. 550-568, 2016.

[15] K. Ferdows, Keeping up with growing complexity of managing global operations, International Journal of Operations \& Production Management, vol. 38, no. 2, pp. 390-402, 2018.

[16] J. Qin, Y. Liu, and R. Grosvenor, A categorical framework of manufacturing for Industry 4.0 and beyond, Procedia CIRP, vol. 52, no. 2016, pp. 173-178, 2016.

[17] K. Ferdows, Relating the firm's global production network to its strategy, in International Operations Network, S. Johansen, S. Farooq, and Y. Cheng, Eds. Aalborg, Denmark: SpringerVerlag London, 2014, pp. 1-11.

[18] M. Pinzone et al., Computers \& industrial engineering: A framwork for operative and social sustainability functionalities in human-centric syber-physical production systems, Computers \& Industrial Engineering, 2018, pp. 1-18.

[19] G. L. Tortorella and D. Fettermann, Implementation of Industry 4.0 and Lean production in Brazilian manufacturing companies, International Journal of Production Research, vol. 56, no. 8, pp. 29752987, 2018.

[20] F. Hecklau, M. Galeitzke, S. Flachs, and H. Kohl, Holistic Approach for Human Resource Management in Industry 4.0, Procedia CIRP, vol. 54, pp. 1-6, 2016.

[21] F. Gregori, A. Papetti, M. Pandolfi, M. Peruzzini, and M. Germani, Digital manufacturing systems: a framework to improve social sustainability of a production site, Procedia CIRP, vol. 63, pp. 436442, 2017.

[22] C. B. Frey and M. A. Osborne, The future of employement: how susceptible are jobs to computerisation?, Technological Forecasting and Social Change, vol. 114, pp. 254-280, 2017.

[23] M. Ghobakhloo, The future of manufacturing industry: a strategic roadmap toward Industry 4.0, Journal of Manufacturing Technology Management, vol. 29, no. 6, pp. 910-936, 2018.

[24] A. Gilchrist, Industry 4.0: The industrial internet of things. Heidelberg: Springer, 2016.

[25] A. Granlund, C. Rösiö, J. Bruch, and P. E. Johansson, Lead factory operationalisation and challenges, Production Planning \& Control, vol. 30, no. 2-3, pp. 96-111, 2019.

[26] P. A. Sarvari, A. Ustundag, E. Cevikcan, E. Kaya, and S. Cebi, Technology roadmap for Industry 4.0, in Industry 4.0: managing the digital transformation, A. Ustundag and E. Cevikcan, Eds. Heidelberg: Springer, 2018, pp. 95-103.

[27] A. Vereecke and R. Van Dierdonck, The strategic role of the plant: testing Ferdows's model, International Journal of Operations \& Production Management, vol. 22, no. 5, pp. 492-514, 2002.

[28] D. Slepniov, B. Wæhrens, and J. Johansen, Dynamic roles and locations of manufacturing: imperatives of alignment and coordination with innovation, Journal of Manufacturing Technology Management, vol. 25, no. 2, pp. 198-217, 2014.

[29] B. Meijboom and B. Vos, Site competence dynamics in international manufacturing networks: instrument development and a test in Eastern European factories, Journal of Purchasing and Supply Management, vol. 10, no. 3, pp. 137-136, 2004.

[30] J. Bruch, A. Granlund, P. Johansson, and C. Rösiö, Core plant capabilities for competitive production development: a literature review, in 23rd EurOMA conference EUROMA, 2016.

[31] M. J. Enright and V. Subramanian, An organizing framework for MNC subsidiary typologies, Management International Review, vol. 47, no. 6, pp. 895-924, 2007.

[32] V. L. da Silva, J. L. Kovaleski, and R. N. Pagani, Technology transfer in the supply chain oriented to industry 4.0: a literature review, Technology Analysis \& Strategic Management, vol. 31, no. 5, pp. 546-562, 2019.

[33] M. Lang, P. Deflorin, H. Dietl, and E. Lucas, The impact of complexity on knowledge transfer in manufacturing networks, Production and Operations Mangement, vol. 23, no. 11, pp. 1886-1898, 2014.

[34] D. V Gibson and R. W. Smilor, Key variables in technology transfer: a field-study based empirical analysis, Journal of Engineering and Technology Management, vol. 8, pp. 287-312, 1991.

[35] R. Van Wijk, J. J. P. Jansen, and M. A. Lyles, Inter- and intra-organizational knowledge transfer: a 
meta-analytic review and assessment of its antecedents and consequences, Journal of Management Studies, vol. 45, no. 4, pp. 830-853, 2008.

[36] A. De Meyer and A. Vereecke, Strategies for itnernational manufacturing, 1994.

[37] Y. Cheng and S. Farooq, The role of plants in manufacturing networks: A revisit and extension, International Journal of Production Economics, vol. 206, no. 2018, pp. 15-32, 2018.

[38] S. Costa Ferreira Junior and A. Fleury, Performance assessment process model for international manufacturing networks, International Journal of Operations \& Production Management, vol. 38, no. 10, pp. 1915-1936, 2018.

[39] X. Li and Q. Wang, Coordination mechanisms of supply chain systems, European Journal of Operational Research, vol. 179, no. 2007, pp. 1-16, 2007.

[40] J. Posada et al., Visual computing as a key enabling technology for industrie 4.0 and industrial internet, IEEE Computer Graphics and Applications, vol. 35, no. 2, pp. 26-40, 2015.

[41] A. Albers, B. Gladysz, T. Pinner, V. Butenko, and T. Sturmlinger, Procedure for defining the system of objectives in the initial phase of an Industry 4.0 project focusing on intelligent quality control systems, Procedia CIRP, vol. 52, pp. 262-267, 2016.

[42] J. Gebhardt, A. Grimm, and L. M. Neugebauer, Developments 4.0 prospects on future requirements and impacts on work and vocational education, Journal of Technical Education, vol. 3, pp. 117-133, 2015.

[43] R. K. Yin, Case study research - Design and Methods, 4th ed. Thousand Oaks, CA: SAGE, 2009.

[44] C. Karlsson, Researching Operations Management. New York, NY: Routledge, 2009.

[45] F. J. Wertz, K. Chamaz, L. M. McMullen, R. Josselson, R. Anderson, and E. McSpadden, Five ways of doing qualitative analysis: Phenomenological psycology, grounded theory, discourse analysis, narrative research, and intuitive inquiry. New York: The Guilford Press, 2011.

[46] C. Voss, N. Tsikriktsis, and M. Frohlich, Case research in operations management, International Journal of Operations \& Production Management, vol. 22, no. 2, pp. 195-219, 2002.

[47] H. Williamson, Research methods for students, academics and professionals: information management and systems. Waga Waga: Quick Print, 2002.

[48] S. B. Merriam, Qualitative research: A guide to design and implementation. San Francisco: JosseyBass, 2009.

[49] K. M. Eisenhardt, Building theories from case study research, Academy of Management Review, vol. 14, no. 4, pp. 532-550, 1989. 